\title{
Ageing in Portugal: regional iniquities in health and health care
}

\author{
Paula Santana* \\ Departamento de Geografia, Faculdade de Letras, Universidade de Coimbra, 3030 Coimbra, Portugal
}

\begin{abstract}
The health of the Portuguese has improved considerably in the last twenty years. Economic and social transformations that have contributed to the progressive amelioration of problems of feeding, sanitation, hygiene, housing and social conditions in general, as well as health services, have had decisive effect on this phenomenon. The spectacular regression of the indicators related to transmitted diseases, infant, perinatal (more than $50 \%$ between 1985 and 1994) and maternal mortality, and the mortality of children 1 to 4 yr old, also reflects this impact. The positive changes that took place in health indicators were reflected in the growth of life expectancy at birth (2.2 yr more for male and 2.3 more for women between 1985 and 1994) in spite of the fact that the difference in life expectancy in relation to EU countries has grown. Improvement in life expectancy, especially in the older age groups, is not normally associated with significant reductions in morbidity. In fact, increased longevity has become more generally associated with chronic illness or other disabilities requiring more medical services and other forms of personal care.

This paper reviews some of the evidence for regional differences in the health status of elderly people in Portugal and considers how health services have reacted to these differences. A preliminary study of health status and patterns of utilisation of elderly people was undertaken. After $30 \mathrm{yr}$ of a National Health Service (NHS) in Portugal we may ask why do inequities in health and access to health care of the elderly population persist? Proactive policies to prevent illness and promote health are still relatively underdeveloped in the Portuguese NHS, and the factors that influence health, such as housing, diet and occupational health hazards, remain largely absent from health and welfare policies. Poor accessibility to health services is the most serious barrier consumers have to face in order to get a medical appointment, and this is more relevant to the oldest part of the population. Geographical location of health care facilities unequally affects the ease of access of different groups of consumers and influences utilisation patterns. Examining the distribution of health services resources is an important way to understand the inequities of access to health and to health care. (C) 2000 Elsevier Science Ltd. All rights reserved.
\end{abstract}

Keywords: Ageing population; Health; Health care; Access; Portuguese National Health Service

\footnotetext{
* Tel.: +351-39-701-669; fax: + 351-39-716-851.

E-mail address: psantana@igifc.min-saude.pt (P. Santana).
}

\section{Introduction}

Demographic changes in Portugal have led to important increases in the size and proportion of the elderly population. The increasing number of older people associated with demographic ageing of the 
population is currently a major concern in Europe and Portugal (Grundy, 1996; Stolnitz, 1996; Watson, 1996), particularly in terms of the health care offered, consumption of health care services (Coleman, 1995; Impallomeni and Starr, 1995; Santana, 1995) and health care expenditures (Taylor and Gooby, 1996; Swift and Severs, 1997). In the United States, Longino (1997, p. 841) has clearly made the point that the culture of medicine is changing, and this change is likely to escalate because of the growth and ageing of the US retirement-age population, the amplification of chronic, rather than acute, illness that accompany ageing, the broad range of noninstitutional options for long-term care, and the interdisciplinary nature of geriatric. The development of the long-term care facilities and geriatric care was also documented in the literature in the United States (Boult et al., 1998), in OCDE countries (Kobayashi, 1997) and in four European countries (Evans, 1997).

Ross et al. (1998) presented a study of needs-based availability of physicians within provinces and across the Canada. Their analysis calculates physician surpluses and deficits in each province using both population growth and ageing data and using age-adjusted physician ratios. Bucket and Curtis (1986) studied the variation between demographic and social groups regarding perceived illness and consultation behaviour. Other authors have written about the health situation of different population groups on health inequalities among regions (Illsley and Le Grand, 1993; Watt, 1993).

However, less research has been carried out in order to identify health inequalities among elderly women and men related to health care usage. Arber and Ginn (1993) used data from the British General Household Survey to analyse the variations in the health of aged women and men by class and material circumstances. They conclude that the level of functional disability is influenced by previous position in the labour market, but not by current material circumstances. Other authors conclude that old people living in the city use general practitioners and outpatient services significantly more often than the people living outside the city do. For the people with no long-standing illness, the difference between urban and rural areas was insignificant.

Blanchette (1995) has focused his attention on the relation between the increasing number of older people and the nation's attention to the costs of health care, arguing that it seems evident that ageing is the major determinant of increasing costs. Dalziel (1996) discusses the problem of ageing and health care in Canada. He covers a wide range of interventions for elderly people, and argues that they are effective and well targeted. Ham and Chande (1996) reports that health conditions and disabilities have greater inci- dence after age 75 and they occur earlier and have more impact on the female population. The growing demands on health care that this process involves are centred on chronic and degenerative diseases and disabilities.

Bonita and Howe (1996) present demographic data that clearly demonstrate the need for recognition of the health of ageing women as a global issue and present the differences between developed and developing countries. The main trend in ageing in developed countries is the increase of the 'oldest old', those $85 \mathrm{yr}$ and older. Although women are the largest group of the 'oldest old', they constitute only a small fraction of the total population of developed countries. They will, however, require access to a wide range of health and long-term care services.

Health problems (their frequency and severity) of the oldest population strata are not distributed randomly throughout the entire population. The improvement of health (life expectancy, invalidity and disability) is accompanied by an increase in the amount of disease situations. Hodes (1997) demonstrates the relationship between longer life expectancy and the increasing of functional problems at advanced ages. The impact of morbidity is unequal from region to region, especially between urban and rural places, poor and rich people. Mobility dysfunction is an important determinant of the poor health of a population. The association of the poverty of the elderly of the rural inland population and poor health is well documented in Portugal (Simões, 1989; Silva, 1988; Santana, 1993).

In Portugal, Silva (1988) studied the influence of conditions of contact and severity of situations related to a collection of indicators: social class, education, household size and physical accessibility. The study revealed that important population subgroups are at a manifest disadvantage with respect to the delivery of health care. Elderly people living in a household with good housing conditions are healthier, use health services more often and are more likely to consult a physician for a serious condition than those living in poor housing conditions do.

Regional disparities are most marked for the groups that seem to have the highest need for medical care in Portugal. According to the balance of evidence, the usage rates of those with probably the greatest need for health care show the greatest decreases in less urbanised areas. Santana (1995) presented the result of a random sample carried out in rural and urban municipalities in the Central Region of Portugal. She concluded that persons living in rural municipalities have more often limited access to health care in hospitals and that age is one of the most important factors that can influence the usage associated with urban/rural places. 
The aim of this paper is to provide a more detailed analysis of the ageing population in Portugal, its health status and to evaluate emerging changes and trends. Particular attention is given to the existing disparities and inequalities in health and healthcare between regions (rural and urban).

\section{Health policies in Portugal}

During the last $25 \mathrm{yr}$, the Portuguese State has assumed an increasingly important role in the Portuguese health care system. The 1976 Constitution substantiated both the social movements and the socio-political 'aggiornamento' of the country and created a National Health Service (NHS). Inspired by the British model, the NHS guarantees the right of health protection to all citizens, based on universal and free access to health care. The result has been an explosion in the demand for care, mainly as a result of the enlargement of sickness protection to $99 \%$ of the Portuguese population, through the assumption of responsibilities for health care in employment-based health schemes, or by direct free access to public health services.

While health care is considered a right and is guaranteed to all by law in Portugal, the limits that are imposed by financial, human and technical resources reduce the real impact of the legislation. Actually, accessibility in the strict sense such as the conversion of need as determined by health professionals or felt by the population, is not the same in all geographical areas and for all groups of the population (age, sex, economic, etc.).

Besides the internal factors of the NHS, one must also consider some others that influence Portuguese contemporary society, sometimes with an unexpected strength. The demographic rarefaction of the inland regions, the urban concentration along the coast, the ageing phenomenon, the growth of functional dependency and the diversifying of health care needs are just some examples of external factors responsible for the present performance of the Portuguese health system. Some of these factors and others directly influence health services access and usage equity, excluding some population groups from care or health goods provision, especially the less affluent and rural populations, and increase individual and family health expenses.

\section{Considerations on health and health differences in Portugal}

The Portuguese population's health has improved considerably in the last twenty years. Economic and
Table 1

Population distribution by broad age groups, ECE region, Southern Europe and Portugal 1950-2025 (\%) ${ }^{\mathrm{a}}$

\begin{tabular}{lllllll}
\hline & Age group & 1950 & 1980 & 1990 & 2010 & 2025 \\
\hline ECE & $0-14$ & 27.2 & 23.4 & 22.6 & 20.7 & 20.3 \\
& $15-59$ & 61.2 & 61.2 & 61.0 & 60.8 & 57.0 \\
& $\geq 60$ & 11.6 & 15.2 & 16.4 & 18.5 & 22.6 \\
\multirow{4}{*}{ Southern Europe } & $0-14$ & 31.3 & 30.3 & 27.5 & 24.0 & 22.2 \\
& $15-59$ & 59.6 & 58.3 & 60.0 & 61.6 & 60.1 \\
& $\geq 60$ & 9.1 & 11.3 & 12.6 & 14.5 & 17.7 \\
Portugal & & & & & & \\
& $0-14$ & 29.5 & 25.9 & 23.8 & 20.8 & 19.3 \\
& $15-59$ & 60.1 & 59.5 & 60.3 & 61.9 & 58.6 \\
& $\geq 60$ & 10.5 & 14.6 & 15.9 & 17.3 & 22.1 \\
& & & & & & \\
& & & & & &
\end{tabular}

${ }^{a}$ Source: United Nations, Demographic Causes and Economic Consequences of Population Ageing. Economic Studies No. 3, Annex Table 1B pp. 35-38.

social transformations (which contributed to a progressive amelioration of feeding, sanitation, hygiene, dwelling and to life conditions in general), as well as health services, have made a decisive contribution to this phenomenon. The spectacular regression of the indicators related to transmitted diseases and infant, perinatal (more than 50\% between 1985 and 1994) and maternal mortality and the mortality in children 1 to 4 yr old reflects the impacts of the improvements in these socio-economic factors. The positive changes that took place in health indicators were reflected in the improvements in life expectancy at birth (2.2 more yr for male and 2.3 for women between 1985 and 1994) in spite of the fact that the difference in life expectancy in comparison to other EU countries has grown.

Increased longevity has become more generally associated with chronic illness or other disabilities requiring more of both medical services and other forms of social and personal care. The goal is not simply a matter of increasing the number of years of life, but includes addressing the social, economic and political factors that determine health and quality of life gained years.

The increasing number and proportion of elderly people in the population has not been accompanied by clear policy measures which consider their needs. This issue is still critical in Portugal. During the 1980s and the 1990s there was a progressive contraction of public community and residential services, as well as a reduction of beds available to the elderly ( 0.49 and 0.21 per 1000 inhabitants in 1985 and 1995), GPs (1.8 and 1.1 per 1000 inhabitants in 1985 and 1995), and longterm inpatient beds in the health centres. Home care (1995: 0.02\%) and long-term hospital beds were significantly reduced. In rural areas, where population ageing 
Table 2

Demographic characteristics, European Union, Portugal and regions, $1991^{\text {a }}$

\begin{tabular}{lccccccc}
\hline & EUR 12 & Portugal $^{\mathrm{b}}$ & North & Centre & Lisbon Tagus V. & Alentejo & Algarve \\
\hline Ageing & 58.0 & 48.5 & 36.3 & 61.3 & 50.3 & 78.9 & 68.1 \\
Mortality rate & 1.01 & 1.04 & 0.92 & 1.20 & 1.01 & 1.39 & 1.27 \\
Dependency ratio (oldest) & 24 & 13.7 & 11.4 & 16.7 & 13.2 & 35.3 & 17.3 \\
\% Old people living alone & & 33.4 & 29.2 & 35.8 & 35.6 & 39.8 & 34.8 \\
Inhabitants per square km & 115 & 105.5 & 163.1 & 72,7 & 276.0 & 20.2 & 68.4 \\
Urban population (\%) & & 73 & 79.5 & 59.7 & 76.2 & 51.7 & 84.6 \\
\hline
\end{tabular}

a Source: Atlas demográfico, MEPAT/DGOTDU, col.7, 1996.

${ }^{\mathrm{b}}$ Continental area.

is more intensive, state responsibilities were progressively transferred to social private institutions or to families. A considerable expansion of community services would be required to return to the level of services of the early 1980s.

The population living in rural areas is even more disadvantaged because these areas have not only a higher proportion of old people, but they also have a higher percentage of old people living alone and a less diversified network of health care services (Table 2). Hospital beds and specialised doctors are concentrated in urban areas. Between 1985 and 1995, the number of public hospital beds in urban areas grew from 3.5 to 4.3 per 1000 inhabitants.

\section{Changes in age structures}

Given the decrease in fertility and mortality (especially child mortality), longer life expectancy (78.6 yr in Portugal and 80.5 in Europe in 1995) is contributing to an increase in the proportion of elderly people in Portugal. Between 1960 and 1980, the effects of declining fertility were more pronounced at the base of the age pyramid than at the top. Since 1990, the effects are becoming more apparent at the top with a growing percentage of the population over 60 (Table 1).

According to United Nations estimates and projections, by 2025 the proportion of those $60 \mathrm{yr}$ and over in Portugal will have almost doubled in comparison to the rates of $1950: 10.5 \%$ of the total population compared to $22.1 \%$ in 2025 . In contrast, the size of the 0 14 age group will decrease between 1950 and 2025 by $10.2 \%$. Portugal has higher values than the southern European countries (from 9.1 to $17.7 \%$, respectively 1950-2025). In the ECE Region, the proportion of elderly people will increase from 11.6 to $22.6 \%$ between 1950-2025, making the projected proportion in Portugal comparable to the percentages for the ECE Region.

If we consider the ageing index (the relation between the population $60 \mathrm{yr}$ and over to the population less than $15 \mathrm{yr}$ old), we can see that the number of the elderly has been growing more than the number of young people In 1950, the index was 35.5. In 2025 it will be 114.5 in Portugal. In comparison, in other European countries the index will go from 42.6 to 111.5 between 1950 and 2025 .

The older segment of the population is increasing and is dominated by women. In 1990, only 35 men aged 75 and over were alive for every 65 women and by 2025 there will be 31 men to 69 women aged 75 and over. Therefore, one of the consequences of the ageing process has been the increasing number of women. In Portugal, the sex ratio for the whole population aged $60 \mathrm{yr}$ and over will decrease regularly between 1950 and 2025 from 55.7 to 46.1. The same trend can be observed in European and southern European countries.

It is also important to say that the growing rhythm of the elderly is higher than the growth of the general population which, in some cases, has decreased. Portugal may currently be considered a young country within the European context. However, we can expect strong and rapid transformations of national demographic structures in the coming years.

\section{Consequences of population ageing}

Ageing of the Portuguese population tends to vary considerably from region to region. The ageing process for the whole Portugal Municipalities and Regions presents many different situations, reflecting disparities in socio-economic development among municipalities and regions. Table 2 identifies some of the differences among Portugal and its administrative regions.

In 1991, the Northern Region of Portugal was the youngest part of the country and one of the youngest regions in Europe, with an ageing index of 36.3. In other regions this indicator was more than or almost the double (Alentejo: 78.9; Algarve: 68.1; Central Region: 61.3). So, there are regional asymmetries in the ageing phenomenon in Portugal, but also inside 
Table 3

Population $65 \mathrm{yr}$ old and over who reported temporary disability by age and region, $1995^{\mathrm{a}}$

\begin{tabular}{lcccccc}
\hline Age & Portugal $^{\mathrm{b}}$ & North & Centre & Lisbon Tagus V. & Alentejo & Algarve \\
\hline $\begin{array}{l}\text { Disability (\%) } \\
\text { 65-74 }\end{array}$ & 12.6 & 10.4 & 17.7 & 13.9 & 10.5 & 7.3 \\
$\geq 75$ & 16.8 & 17.0 & 19.8 & 20.5 & 13.2 & 9.2 \\
Number of days & & & & & 6.2 & 6.2 \\
$65-74$ & 7.2 & 8.7 & 6.7 & 7.5 & 8.4 & 6.2 \\
$\geq 75$ & 9.3 & 11.4 & 8.9 & 9.3 & & \\
\hline
\end{tabular}

${ }^{a}$ Source: National Health Survey, 1995.

${ }^{\mathrm{b}}$ Continental area.

the regions. In Table 2 we can also see the distribution of the urban population: Alentejo and Central Region are the less urbanised regions. Ageing is high in Alentejo, Algarve and the Central Region. Inside these regions we can find the highest values for ageing in rural municipalities.

Ageing in rural areas is higher, began earlier and is more rapid than in urban areas. Throughout the period, 1950-1991, the pronounced migration of young adults from rural (low proportion of inhabitants per square $\mathrm{km}$ ) to urban areas led to significant antiageing or rejuvenating impacts on urban destinations. Indeed, in urban areas, where internal migration was especially dominant over natural increase, its impacts resulted in the declines of average age of the population and reductions in the upper-age proportions. By contrast, migration movements out of rural areas consistently contribute to ageing within rural areas.

The other problem associated with the ageing of the population at the regional level is the proportion of people who live alone. The highest values of old people living alone were found in Alentejo and Central Region. So, it is the less populated areas (where a significant percentage of population is concentrated in small villages with dominant rural characteristics) that present higher values (both absolute values and relative values) of old people and of old people living alone.
Alentejo and Central are the Portuguese regions with the highest values on those indicators.

\section{Health consequences of population ageing}

The ageing problem is related to factors such as the growth of dependants, disabled and people with chronic diseases, family destructuring, changes in family patterns, the increasing isolation of aged people and mobility problems, among others. A health survey carried out in Portugal every ten years (National Health Survey, 1987, 1995), shows that chronic diseases causing disability become more prevalent with advanced age - around $46 \%$ of the elderly suffer from one or more of such diseases. Increased life expectancy has been accompanied by a prolongation of expectation of life with disability and with a slight increase in the prevalence of chronic diseases of old age. For example, between 1987 and 1995, chronic conditions that the older population suffered increased significantly (e.g., skeletal diseases grew from 18 to $29 \%$ ).

In 1995, according to the NHS, $53.8 \%$ of the Portuguese aged 75 and over self-assessed themselves as in a bad or very bad health condition. In this age group, $16.8 \%$ reported short-term disability in the two weeks prior to the interview. Table 3 shows the re-

Table 4

Population $65 \mathrm{yr}$ old and over by number of bed-days in two weeks prior to interview by age and region, $1995^{\mathrm{a}}$

\begin{tabular}{|c|c|c|c|c|c|c|}
\hline Age & Portugal & North & Centre & Lisbon Tagus V. & Alentejo & Algarve \\
\hline \multicolumn{7}{|c|}{ Patients (\%) } \\
\hline $65-74$ & 7.4 & 5.4 & 11.6 & 8.1 & 6.9 & 5.8 \\
\hline$\geq 75$ & 11.7 & 13.6 & 14.0 & 12.6 & 7.0 & 3.0 \\
\hline \multicolumn{7}{|c|}{ Number of days } \\
\hline $65-74$ & 7.2 & 7.7 & 6.5 & 7.7 & 7.4 & 6.7 \\
\hline$\geq 75$ & 10.0 & 11.5 & 9.1 & 9.8 & 10.4 & 8.1 \\
\hline
\end{tabular}

\footnotetext{
${ }^{a}$ Source: National Health Survey, 1995.
} 
Table 5

Population $65 \mathrm{yr}$ old and over who reported days of ill-health in the two weeks prior to interview by chronic and acute causes by age and region, $1995(\%)^{\mathrm{a}}$

\begin{tabular}{lllllrr}
\hline Age & Portugal & North & Centre & Lisbon Tagus V. & Alentejo & Algarve \\
\hline Chronic causes & & & & & & \\
$65-74$ & 31.2 & 30.5 & 35.3 & 29.4 & 41.9 & 16.0 \\
$\geq 75$ & 35.1 & 35.1 & 34.4 & 33.3 & & 22.2 \\
Acute causes & & & & 13.8 & 10.1 & 12.2 \\
$65-74$ & 11.8 & 9 & 12.9 & 15.7 & 8.2 & 9.9 \\
$\geq 75$ & 10.9 & 7.4 & 12.2 & & \\
\hline
\end{tabular}

a Source: National Health Survey, 1995.

gional variations. It is the population of the Central Region that suffers more frequently with physical limitations when facing a disease, as well as the North Region of Portugal. The average number of bed-days of the sick population (aged $74 \mathrm{yr}$ and over) - in the two weeks prior to the interview - is also higher in these regions. The average in Alentejo is 10.4 and in the North 11.5 days (Table 4).

We can also consider the age group 65 and over,

Table 6

Hospitalisation, rate per 1000 inhabitants, for different pathologies, $1995(\%)^{\mathrm{a}}$

\begin{tabular}{|c|c|c|c|}
\hline Age groups & MF & M & $\mathrm{F}$ \\
\hline \multicolumn{4}{|c|}{ Circulatory system diseases } \\
\hline $0-64$ & 4.7 & 5.7 & 3.7 \\
\hline $65-84$ & 38.4 & 46.6 & 32.4 \\
\hline $85+$ & 72.0 & 83.8 & 66.8 \\
\hline Total & 10.0 & 11.1 & 9.0 \\
\hline \multicolumn{4}{|c|}{ Respiratory system diseases } \\
\hline $0-64$ & 4.5 & 5.4 & 3.6 \\
\hline $65-84$ & 12.3 & 17.3 & 8.6 \\
\hline $85+$ & 32.6 & 49.0 & 25.6 \\
\hline Total & 5.9 & 7.1 & 4.7 \\
\hline \multicolumn{4}{|c|}{ Fractures and traumas } \\
\hline $0-64$ & 6.0 & 8.8 & 3.4 \\
\hline $65-84$ & 9.6 & 9.1 & 9.9 \\
\hline $85+$ & 30.9 & 24.2 & 33.9 \\
\hline Total & 6.8 & 8.9 & 4.8 \\
\hline \multicolumn{4}{|l|}{ Neoplasms } \\
\hline $0-64$ & 5.0 & 3.7 & 6.2 \\
\hline $65-84$ & 19.5 & 25.5 & 15.1 \\
\hline $85+$ & 20.9 & 32.0 & 16.2 \\
\hline Total & 7.1 & 6.5 & 7.8 \\
\hline \multicolumn{4}{|c|}{ Genital and urinary system } \\
\hline $0-64$ & 4.6 & 3.0 & 6.2 \\
\hline $65-84$ & 9.3 & 11.5 & 7.7 \\
\hline $85+$ & 11.3 & 18.6 & 8.2 \\
\hline Total & 5.3 & 4.1 & 6.5 \\
\hline
\end{tabular}

a Source: a Saúde dos Portugueses, DGS, 1997, p. 72. which reported days of ill health due to chronic causes in the two weeks prior to their interview. Table 5 shows the highest values are for Alentejo and the North.

Only $1.1 \%$ of retired people received in-patient care in hospitals. The average duration of such care was similar in 1987 and 1995 (7 and 7.8 days respectively). The lowest rates were registered in the Algarve $(0.4 \%$ and 4.3 days) and Alentejo (1\% and 5.7 days), in 1995. Table 6 shows the hospitalisation rate by pathologies. The highest values correspond to the neoplasms.

The sample population $65 \mathrm{yr}$ and over who reported one or more long-term disabilities are presented in Table 7.

Mobility problems as measured by the ability to walk up and down the stairs several times was the most frequently identified in Portugal (33.3 and 50.7\%, respectively for 65-74 and 75 and over). An substantial number of aged people needs help with routine activities such as household chores $(39.6 \%, 75$ and over), and with eating, bathing or dressing $(17.6 \%, 75$ and over). Differences in the percentage of elderly people with long-term disabilities varied by region. Alentejo and Central Portugal were the regions with the highest percentage of disabled persons. It is in these geographical areas that we find more sick people, either with chronic (such as high blood pressure and backache) or acute diseases (see Table 8).

The ageing of the population is also linked to a large increase in the number of cerebro-vascular, cardiovascular, respiratory, cancer and gastrointestinal diseases cases reported. Between 1987 and 1995, the morbidity pattern changed. What stands out is the relative decrease in diseases of the digestive and circulatory systems and an increase in mental disorders and neoplasms.

The ageing of the population in Portugal is also at the heart of important changes in health care need and usage. The 1987 and 1995 NHS show the variations in health needs and consumption of different medical services and goods by age. When facing a disease, the use of a doctor is not a regular procedure for the elderly. 
Table 7

Population $65 \mathrm{yr}$ old and over who reported long-term, 1995. Disability by disability and region, $1995(\%)^{\mathrm{a}}$

\begin{tabular}{|c|c|c|c|c|c|c|c|}
\hline Disability & Age groups & Portugal $^{\mathrm{b}}$ & North & Centre & Lisboa Tagus V. & Alentejo & Algarve \\
\hline \multicolumn{8}{|c|}{ Walk on level ground } \\
\hline & $65-74$ & 15.0 & 12.7 & 16.0 & 15.6 & 20.5 & 8.5 \\
\hline & $\geq 75$ & 31.0 & 28.4 & 30.6 & 35.6 & 36.1 & 22.0 \\
\hline \multicolumn{8}{|c|}{ Walk up and down stairs several times } \\
\hline & $65-74$ & 33.3 & 31.7 & 42.8 & 29.6 & 39.1 & 19.7 \\
\hline & $\geq 75$ & 50.7 & 48.2 & 53.2 & 51.3 & 55.6 & 43.3 \\
\hline \multicolumn{8}{|c|}{ Getting to and out of bed } \\
\hline & $65-74$ & 15.0 & 11.4 & 21.3 & 15.6 & 17.6 & 5.4 \\
\hline & $\geq 75$ & 27.1 & 22.6 & 31.1 & 27.9 & 32.3 & 19.4 \\
\hline \multicolumn{8}{|c|}{ Household chores } \\
\hline & $65-74$ & 25.4 & 23.3 & 40.1 & 22.9 & 22.5 & 12.5 \\
\hline & $\geq 75$ & 39.6 & 33.5 & 52.4 & 37.8 & 39.2 & 30.3 \\
\hline \multicolumn{8}{|c|}{ Getting dressed and undressed } \\
\hline & $65-74$ & 14.3 & 10.9 & 21.0 & 13.9 & 16.4 & 6.8 \\
\hline & $\geq 75$ & 17.6 & 22.7 & 32.6 & 25.5 & 34.1 & 22.6 \\
\hline
\end{tabular}

${ }^{a}$ Source: National Health Survey, 1995.

${ }^{\mathrm{b}}$ Continental area.

Many elderly people took a medicine that they knew or was recommended by friends $(61 \%$ in 1987 and $49 \%$ in 1995), others underwent treatments made at home $(29 \%$ in 1987 and $15.6 \%$ in 1995$)$ or changed their diets (17.1\% and $11.8 \%$, respectively) and some did not do anything $(11.3 \%$ and $18.2 \%$ in 1987 and 1995). In contrast, there were hardly any changes in the use of medical appointments between the two time periods $(38.6 \%$ compared to $39.6 \%)$.

Nevertheless, the procedures adopted by the population that was sick in the two weeks prior to the interview present differences from region to region (Table 9). Once again, the elderly people of the Central Region and Alentejo demonstrate a different set of health behaviours compared to the other regions or the country as a whole. These two geographical areas also have the lowest health care usage. High proportions of the population of these regions took medi- cines that they already knew or simply did not do anything (see Table 9). On the other hand, the people aged 75 and over of Lisbon and Tagus Valley (where rates are considerably superior to the average of the country) indicated more often that they make a medical appointment when they felt sick.

When they believe they are sick, the people of Lisbon and Tagus Valley try to overcome their illnesses using healthcare services, while people from other regions do nothing to put an end to their health problem or they use their own previous experience dealing with disease. The elderly populations of Central and Northern Portugal stand out in this regard.

General practitioner appointments in Health Centres (Primary Health Care) represent $84 \%$ (81.8 and $86 \%$ for the age groups 65-74 and more than 75) of the total medical appointments in Portugal. The elderly population of Lisbon and the Tagus Valley show a

Table 8

Population 65 yr old and over who reported chronic conditions (high blood pressure and lower backache) by age and region, 1995 $(\%)^{\mathrm{a}}$

\begin{tabular}{lllllll}
\hline Chronic conditions & Portugal $^{\mathrm{b}}$ & North & Centre & Lisbon Tagus V. & Alentejo & Algarve \\
\hline $\begin{array}{l}\text { High blood pressure } \\
\text { 65-74 }\end{array}$ & 37.6 & 34.2 & 43 & 35.9 & 35.9 & 34.2 \\
$\geq 75$ & 36.4 & 29.2 & 39.8 & 36.7 & 36.9 & 34.5 \\
Lower backache & & & & & 58.1 & 52.1 \\
$65-74$ & 57.2 & 23.4 & 72.0 & 37.8 & 56.8 & 52.7 \\
$\geq 75$ & 51.2 & 24.5 & 69.2 & 39.2 & & \\
\hline
\end{tabular}

\footnotetext{
${ }^{a}$ Source: National Health Survey, 1995.

${ }^{\mathrm{b}}$ Continental area.
} 
Table 9

Procedures adopted by population $65 \mathrm{yr}$ old and over who reported one or more days of ill-health in the two weeks prior to interview, by procedures, age and region, $1995(\%)^{\mathrm{a}}$

\begin{tabular}{|c|c|c|c|c|c|c|c|}
\hline Procedures & Age groups & Portugal $^{\mathrm{b}}$ & North & Centre & Lisbon Tagus V. & Alentejo & Algarve \\
\hline \multicolumn{8}{|c|}{ Home remedies } \\
\hline & $65-74$ & 15.4 & 10.1 & 24.0 & 16.8 & 9.0 & 13.5 \\
\hline & $\geq 75$ & 14.8 & 10.1 & 23.6 & 16.2 & 9.8 & 10.0 \\
\hline \multicolumn{8}{|c|}{ Changed diet } \\
\hline & $65-74$ & 12.3 & 12.3 & 4.4 & 13.8 & 8.8 & 8.7 \\
\hline & $\geq 75$ & 11.1 & 10.4 & 14.9 & 11.5 & 6.7 & 10.0 \\
\hline \multicolumn{8}{|c|}{ Take self-known medicines } \\
\hline & $65-74$ & 49.4 & 44.6 & 48.8 & 55.5 & 50.0 & 42.3 \\
\hline & $\geq 75$ & 47.5 & 44.5 & 46.3 & 53.2 & 48.9 & 41.3 \\
\hline \multicolumn{8}{|c|}{ To see a doctor } \\
\hline & $65-74$ & 39.4 & 42.7 & 37.4 & 40.1 & 34.1 & 48.1 \\
\hline & $\geq 75$ & 37.4 & 40.0 & 30.7 & 42.3 & 33.6 & 43.8 \\
\hline \multicolumn{8}{|l|}{ Did nothing } \\
\hline & $65-74$ & 17.5 & 19.0 & 17.8 & 17.1 & 18.9 & 10.6 \\
\hline & $\geq 75$ & 19.3 & 20.8 & 21.3 & 15.9 & 17.4 & 15.0 \\
\hline
\end{tabular}

' Source: National Health Survey, 1995.

${ }^{b}$ Continental area.

lower usage rate than the country's average use of general practitioners' appointments, but the elderly population of this region more frequently make appointments with specialists. Appointments with orthopaedic, cardiology and psychiatry specialists are the most common (Table 10).

Table 10

Population $65 \mathrm{yr}$ old and over who reported having doctor's visits in the three months prior to interview by type of last visit, age and region, $1995(\%)^{\mathrm{a}}$

\begin{tabular}{|c|c|c|c|c|c|c|c|}
\hline Type of doctor's visit & Age groups & Portugal $^{\mathrm{b}}$ & North & Centre & Lisbon V. Tejo & Alentejo & Algarve \\
\hline \multicolumn{8}{|l|}{ Cardiology } \\
\hline & $65-74$ & 3.6 & 5.0 & 2.4 & 3.9 & 3.2 & 2.9 \\
\hline & $\geq 75$ & 2.4 & 2.0 & 3.0 & 3.8 & 1.4 & 2.9 \\
\hline \multicolumn{8}{|l|}{ GP's visit } \\
\hline & $65-74$ & 81.8 & 82.4 & 84.0 & 75.0 & 87.0 & 85.4 \\
\hline & $\geq 75$ & 86.0 & 82.5 & 90.0 & 80.0 & 91.0 & 88.1 \\
\hline \multicolumn{8}{|l|}{ Dentist } \\
\hline & $65-74$ & 0.9 & 0.8 & 1.2 & 1.3 & 0.2 & 0.0 \\
\hline & $\geq 75$ & 0.2 & 0.8 & 0.3 & 0.5 & 0.2 & 0.4 \\
\hline \multicolumn{8}{|l|}{ Ophthalmologist } \\
\hline & $65-74$ & 2.8 & 2.6 & 2.5 & 4.2 & 0.2 & 0.5 \\
\hline & $\geq 75$ & 3.0 & 2.2 & 3.4 & 4.3 & 0.2 & 0.0 \\
\hline \multicolumn{8}{|l|}{ Orthopedics } \\
\hline & $65-74$ & 2.0 & 1.3 & 1.7 & 3.2 & 1.6 & 1.9 \\
\hline & $\geq 75$ & 1.4 & 2.6 & 0.2 & 4.3 & 1.4 & 2.9 \\
\hline \multicolumn{8}{|l|}{ Psychiatry } \\
\hline & $65-74$ & 0.5 & 0.6 & 0.1 & 9.4 & 1.6 & 1.2 \\
\hline & $\geq 75$ & 0.4 & 0.7 & 0.5 & 0.1 & 1.2 & 0.2 \\
\hline \multicolumn{8}{|l|}{ Urologist } \\
\hline & $65-74$ & 1.3 & 1.0 & 1.3 & 1.7 & 0.2 & 0.7 \\
\hline & $\geq 75$ & 1.3 & 1.9 & 1.0 & 1.6 & 0.2 & 0.7 \\
\hline
\end{tabular}

\footnotetext{
${ }^{a}$ Source: National Health Survey, 1995.
}

${ }^{b}$ Continental area. 
Table 11

Population $65 \mathrm{yr}$ old and over by number of doctor's visits in the three months prior to interview by age and region, $1995^{\mathrm{a}}$

\begin{tabular}{llllllll}
\hline & Age groups & Portugal $^{\mathrm{b}}$ & North & Centre & Lisbon Tagus V. & Alentejo & Algarve \\
\hline Doctor's visits \% & & & & & & & \\
& $64-75$ & 60.7 & 47.7 & 68.1 & 68.9 & 64.9 & 56.6 \\
& $\geq 75$ & 65.7 & 40.8 & 64.9 & 72.1 & & 59.2 \\
Doctor's visits number & & & & & & 2.5 & 2.3 \\
& $64-75$ & 2.6 & 2.3 & 2.9 & 2.7 & 2.3 & 2.5 \\
& $\geq 75$ & 2.6 & 2.4 & 2.9 & 2.6 & & \\
\end{tabular}

a Source: National Health Survey, 1995.

${ }^{\mathrm{b}}$ Continental area.

According to the first National Health Inquiry (1987), 57\% of the population aged $60 \mathrm{yr}$ and over indicated that they had 2.8 doctor's visits in the three months prior to the interview. In 1995, 60.7\% had 2.6 doctor's visits (Table 11). The actual decrease in health care utilisation with ageing does not fit with the expected situation (ageing $=$ more disability and disea$\mathrm{se}=$ more health care consumption).

In Portugal, the reasons that lead people to look for a doctor more frequently are related to the diseases of osteo-muscular system $(14.8 \%)$, circulatory system $(15.1 \%)$, respiratory system $(12.8 \%)$ and digestive system $(10.9 \%)$.

The analysis has been focussed on perceived needs, which may be or not converted into concrete demands, depending on the different regions of the country. Although many important variations have been identified among the different regions, either at the level of health needs or regarding service usage, it seems that the interregional differences, mainly between more or less urbanised areas, are extremely relevant to explain the health and health care differences. It is also important to mention that Portugal's rural areas (Alentejo and Central Region) consistently show the impacts of a growing ageing population. Nevertheless, the difficulty in presenting results can be found in the lack of surveys with the necessary geographical disaggregation to support detailed and accurate information on the usage of the health services by the population (by ages and service types according to location - rural or urban).

\section{Discussion of results}

Population ageing is a reality in Portugal. In 2010 there will be 17 people $60 \mathrm{yr}$ old or more for each 100 inhabitants. These values will be higher in the regions of Alentejo, Algarve and Central. It will be also in these regions that disabilities and dependency caused by chronic or acute diseases will be more significant.
Paradoxically, these regions have low healthcare services usage rates.

We know that utilisation (frequency and rates) of health services is not always positively related with health needs. Distance, for example, plays an important role. Besides distance, some other factors are associated with the capability of the oldest part of the population living in peripheral areas to use health services. The association of social and geographical factors with a population's quality of life status is well known.

There are two groups of variables related to health services utilisation and consumption: physical and individual characteristics (age, sex, income, family structure, etc.). While health service utilisation can be manipulated by decision makers through the implementation of actions to improve health services accessibility, affecting individual characteristics can only partially be modified by policy. Nevertheless, a more adequate policy will improve the accessibility of the older, less affluent and peripheral population. The understanding of geographic accessibility should consider the localisation of health services, the spatial distribution of consumers and their characteristics and mobility, because the mere existence of services does not assure their adequate utilisation.

Equity and accessibility of healthcare does not depend exclusively on there being offered. They also are result of felt health needs of the oldest strata of population, life styles and social-economical conditions.

In 1991, the Portuguese population more than $65 \mathrm{yr}$ of age represented about $14 \%$ of the total residents and the ageing index reached a value of $46.5 \%$. Nevertheless, there is an obvious dichotomy between the north and south and the urban and rural in the demographic structure. The Northern Region is the youngest part of the country and even of Europe. However, in some municipalities inland of this region, we can notice high ageing levels. The Region of Lisbon and of the Tagus Valley approximates the aver- 
age of the country and is one of the most urban. Alentejo, which is less populated, has a higher percentage of old people. The Central Region and Alentejo present the highest ageing indexes and higher values of old people living alone. According to the increase in the ageing index in these regions, the health needs were supposed to be higher and to have consequences for the usage of health services. After the results presented in this essay, we can see that the impact of ageing is not so visible as it should be and that health and healthcare differences in Portugal are highlighted by an analysis of the usage of specialised medical care. It is also in these areas that we can register the highest mortality rates by cerebro-vascular diseases, malign tumours, heart diseases, diabetes mellitus, atherosclerosis, suicide and homicide of the country are registered. For example, Alentejo is where the population shows a higher need for health care - there is a higher percentage of the population with declining health status caused by chronic or acute diseases - given several types of long-standing illnesses with high percentages. Nevertheless, the usage of medical care is relatively low. Although the population of this region seems to be the one with the greatest need of health care, it is not the one where the highest number of medical appointments is made by those facing a perceived need (a disease of one or more days). When a medical appointment is made, it is almost always with a general practitioner. So, there are inequalities among the ageing people related to their health.

A key problem is accessibility to health care. When health services are freely provided at the time of consumption, like the services offered by the Portuguese NHS, two of the most serious barriers that elderly consumers still face in order to get healthcare are travel costs and the lack of mobility. The location of hospitals unequally affects the ease of access of different groups of consumers and influences utilisation patterns: higher for resident of urban places and lower for the rural residents.

In the provision of Public Health Services, the location of health units and medical staff (public and private) is, both quantitatively and qualitatively, a disadvantage for elderly people from rural areas who face greater problem in using the health system than the urban population. The geographical disparities are most marked for the groups likely to have the highest need for medical care. The balance of evidence is that it is those with probably the greatest need for healthcare are least likely to use specialised care in rural areas.

There is a lot to do to improve the health status of older people and their accessibility to health care. It is necessary to develop new models of health care production and delivery for the elderly, to face the challenges of new health problems, considering demographic changes but, also, individual behaviours, life styles and goods and services consumption habits. The Health Strategy for 2002, a document of the Portuguese Health Ministry, presents some guidelines for the future: (1) training health professionals on gerontology and geriatric care; (2) implementation of local networks of integrated home care; (3) development of rehabilitation health care for the elderly. Some other important issues are also addressed by the above mentioned document, namely those concerning the diagnostic of health needs and better support to older people by families, local communities or other entities that can contribute to improve elderly quality of life.

It is also important to eliminate geographical obstacles to accessibility, through integrated home and long-term inpatient care. This will determine the need for more significant investment in such facilities and services, considering regional differences and inequities.

\section{Conclusion}

Comparing findings of the present paper with others reflecting the experience of other countries with different health policies reveals the potential advantage of the primary care health policy in Portugal. It is suggested that particularly in rural areas and mainly for the oldest strata of the population, health centres and branches (rural units) could play an important role in access to health. But this only addresses accessibility to primary health care services and, without some kind of offer to create home care and long-term inpatient facilities that are very important to the elderly, there will be other types of accessibility problems. Because of the lack of linkage and articulation of health care levels, accessibility to specialised care (hospitals) is not easy or facilitated by the primary level. At the same time, the highest percentages of older people in Portugal are found in rural municipalities far from the main roads and the provision of hospital care.

There is an urgent need for the Portuguese health policy to ensure that rational priorities goals/objectives, strategies, and programs are in place to enhance prevention and disease control and better health for the oldest people. Future elderly populations will increase both because of past increases in fertility and improvement in upper-age mortality. If extension of life expectancy or life span for the elderly implies more years spent with poor health, it will lead to an increase in health consumption. But if living longer means better health, then health care consumption may decrease, at least at the hospital care level, due to the strengthening of primary and tertiary care. In the first case, the demographic factor would have a stronger negative 
effect, while in the second case there would be a compensatory effect on health care outlays.

Demographic factors are obviously important in the definition of the pattern of medical utilisation and expenditures, as changes in both the absolute size of population and its age structure affect demand for medical services. Older age groups require medical care more frequently, for longer periods and at higher cost than other groups.

At present, no model can be used to assess how demographic changes can influence health utilisation services and health expenditures. According to studies based on the decomposition of health expenditure growth rates or age-cost profiles, demographic changes have only contributed to a minor part of observed increases in public health expenditure. But maybe the ageing problem has not yet received all the attention it deserves. The politicians should provide this population group with the necessary conditions for health - caution, maintenance or cures - and with the appropriate care (type, quality and frequency). But we know that longer life expectancy means a high incidence of disability and may be a more frequent cause of healthcare consumption. At the same time, social services, whether public or private, cannot fill the gap left by the decline of family support.

The varying patterns in the experience of illness and use of medical services between different demographic and social groups continue to stimulate discussion.

Research studies carried out in many countries on the effects of the various factors of healthcare usage clarify the effects of individual variables. Nevertheless, the difficulty to achieve their precise role deals with the interrelationship between the variables and the specificity of each country concerning health policy and the cultural structure of the population.

\section{Acknowledgements}

A special acknowledgement to Professor Mark Rosenberg who supported the English version of this paper.

\section{References}

Arber, S., Ginn, J., 1993. Gender and inequalities in health in later life. Social Science \& Medicine 36 (1), 46.

Blanchette, P.L., 1995. Age-based rationing of health care. Hawaii Medicine Journal 54 (4), 507-509.

Bonita, R., Howe, A.L., 1996. Older women in an aging world: achieving health across the life course. World Health State Quaternaries 49 (2), 134-141.
Boult, C., Boult, L., Pacala, J.T., 1998. Systems of care for older population of the future. Journal of the American Geriatrics Society 46 (4), 499-505.

Bucket, D., Curtis, S., 1986. Socio-demographic variations in perceived illness and the use of primary care: the value of community survey data for primary care services planning. Social Science \& Medicine 23, 737-744.

Coleman, B.J., 1995. European models of long-term care in the home and community. International Journal Health Services 25 (3), 455474.

Dalziel, W.B., 1996. Demographics, aging and health care: is there a crisis? Canadian Medical Association 155 (11), 1555-1560 (editorial comment).

Departamentos de Estudos e Planeamento da Saúde, 1989. Inquérito Nacional de Saúde 1987. In: Quadros Referentes ao Continente e Área Metropolitana de Lisboa, 1. Ministério da Saúde, Lisboa.

Departamentos de Estudos e Planeamento da Saúde, 1998. Inquérito Nacional de Saúde 1995/1996: região Norte, Centro, Lisboa e Vale do Tejo, Alentejo, Algarve e Continente. Ministério da Saúde, Lisboa.

Direcção Geral do Ordenamneto do Território e Desenvolvimento Urbano, 1996. Atlas Demográfico. Caracterização e Perpectivas NUTE II e III. DGOTDU, Lisboa.

Evans, L.K., 1997. Trends in aging care in Scotland and Scandinavia. Journal of Gerontology Nurse 23 (9).

Grundy, E., 1996. Population Ageing in Europe. In: Coleman, D. (Ed.), Europe's Population in the 1990s. Oxford University Press, pp. 267-296.

Ham, Chande, R., 1996. Aging: a new dimension in health in Mexico. Salud Publica Mexico 38 (6), 409-418.

Hodes, R.J., 1997. Meeting challenges of an aging population. Academic Medicine 72 (19), 892-893.

Illsley, R., Le Grand, J., 1993. Regional inequalities in mortality. Journal of Epidemiology and Community Health 47 (6), 449.

Impallomeni, M., Starr, J., 1995. The changing face of community and institutional care for the elderly. Journal of Public Health Medicine 17 (2), 171-178.

Kobayashi, R., 1997. Développer les soins de santé et la prise en charge de longue durée dans une société vieillissante. In: Famille, Marché et Collectivité, Equité et Efficience de la Politique Sociale, Études de Politiques Sociale, 21. OCDE.

Longino, C.F., 1997. Pressure from our aging population will broaden our understanding of medicine. Academic Medicine 72 (10), 841-847.

Ross, N.P., Bradley, J.E., Frasoo, R., Shanahan, M., 1998. How many physicians does Canada need to care for our aging population? CMAJ 158 (19), 1275-1284.

Santana, P., 1995. Acessibilidade e Utilização dos Serviços de Saúde. Ensaio Metodológico em Geografia da Saúde, CCRC/ARSC, Coimbra. Saúde/95, Ministério da Saúde, Lisboa.

Silva, M.C.T., 1988. Health services usage in the Ribeira de Pena Concelhos of Portugal. Ph.D. thesis, University of Exeter, Exeter.

Simões, J.M., 1989. Saúde: o Território e as Desigualdades. Ph.D. thesis, Universidade de Lisboa, Lisboa.

Stolnitz, G., 1996. Overview. In: Demographic Causes and 
Economic Consequences of Population Ageing. United Nations Economic Commission for Europe and United Nations Populations Fund, Economic Studies, vol. 3, pp. $1-12$.

Swift, C.G., Severs, M.P., 1997. The challenges of service provision. Age Aging 26 (Suppl. 4), 30-42.

Taylor, Gooby, P., 1996. The future of health care in six
European countries: the views of policy elites. International Journal of Health Services 26 (2), 203-219.

Watson, R., 1996. Europe's aging population (news). British Medical Journal 312 (7044), 1442.

Watt, G.C., 1993. Differences in expectation of life between Glasgow and Edinburgh. Implications for health policy in Scotland. Health Bulletin Edinburgh 51 (6), 407-4171. 